\title{
THE INTERVENTIONAL EFFECT OF COMBINED
}

\author{
REDUCING OCCUPATIONAL UPPER EXTREMITY
}

USE AND PNEUMATIC PUMP ON BREAST CANCER

\section{RELATED LYMPHEDEMA}

\author{
By \\ ${ }^{1}$ Mansour N, ${ }^{2}$ Kahla Z and ${ }^{3}$ Ewies M \\ ${ }^{1}$ Department Of Occupational and Environmental Medicine, Faculty of Medicine, Cairo University, \\ ${ }^{2}$ Department Of Physical Therapy for Surgery, Faculty of Physical Therapy, Cairo University, \\ ${ }^{3}$ Physical Therapist, National Cancer Institute, Egypt.
}

\begin{abstract}
Background: Breast cancer related lymphedema (BCRL) treatment continues to be a distressing and frequent problem. Aim of Work: To detect the relation between the level of hand use in different occupation and both the grade and stage of BCRL and to determine whether the combined effect of decreased occupational work load of the upper extremities and the use of pneumatic compression pumps could manage BCRL effectively. Materials and Methods: 68 patients with BCRL were selected. Age, body mass index (BMI), history of infection, lymphedema grade and stage, sequential circumferential arm measurements, Visual Analog Scale (VAS), handgrip strength were assessed. All patients underwent pneumatic compression pumping for 3 months combined with changing in their level of hand use. Results: Before intervention, the grades and stages of lymphedema showed statistically significant differences among the different occupational groups $(\mathrm{p}<0.05)$. After applying our interventional measures, statistical significant decrease was detected regarding the VAS and significant increase in right hand grip was observed among one group while the difference of sequential circumferential measurements showed decrease in their values but not to the significant level. Conclusion: Occupations requiring more upper extremity activity had the worst lymphedema clinical grade and stage status. More researches are needed to support our
\end{abstract}


findings and to assess the combined effect of decreased occupational work load of the upper extremities and the use of pneumatic compression pumps.

Key words: Breast cancer related lymphedema, Occupation, Pneumatic pumps, Visual Analog Scale, Handgrip Strength

\section{Introduction}

Patients with breast cancer undergo surgical treatment (mastectomy) accompanied by axillary node dissection and radiotherapy. These treatments impair lymphatic drainage of the affected upper limb, and place patients at risk for secondary lymphedema, which has been reported at rates ranging from $10.0 \%$ to $49.0 \%$. Breast cancerrelated lymphedema (BCRL) is defined as edema in the upper extremity, due to the insufficient drainage of lymph; a serious and disabling complication of breast cancer treatment (Kaviani and Lotfi, 2006).Treatment-induced damage interrupts lymph transport such that lymph volume exceeds transport capabilities eventually leading to abnormal accumulation of tissue protein, edema, and chronic inflammation within the arm (Mortimer, 1998).

The incidence of lymphedema after breast cancer treatment is variable and has been reported between $0.2 \%$ and $65.0 \%$ (Shah and Vicini, 2011 and Rezaianzadeh et al, 2009). BCRL symptoms have been reported with all treatment modalities. It can occur within days or up to decades postoperatively in breast cancer survivors, which makes follow-up difficult in cases of delayed development (National Cancer Institute, 2014).

There are multiple risk factors for development of BCRL including: obesity (BMI $\geq 30$ ); , sedentary lifestyle; breast cancer surgery; radiation therapy; post-surgical infection; radiation skin reaction; age; comorbid conditions and medication usage; and genetic predisposition (Armer et al,2013).Also, employment status, age, treatment on dominant side, education level and smoking are from the risk factors (Zhu et al,2014).

The risk reduction practices recommended by the National Lymphedema Network (National Lymphedema Network, 2008) include skin care (avoiding trauma or injury to reduce infection risk), carefully physical activity with monitoring for symptoms, 
avoiding limb constriction (e.g., elastic watch bands that leave a mark which might occlude flow of lymph), wearing a compression garment if prescribed, and avoiding extremes of temperature. As employment status (upper extremity use) is one of the risk factors in a multi-factorial etiology of BCRL (Zhu et al, 2014).Therefore, classification of occupations with different upper extremity activity duration is expected to distinguish high-risk patients for BCRL.

\section{Aim of work}

To detect the relation between the level of hand use in different occupation and both the clinical grade and stage of BCRL and to determine whether the combined effect of decreased occupational work load of the upper extremities and the use of pneumatic compression pumps could manage BCRL effectively.

\section{Consent:}

Prior to this study, approval of the Rehabilitation Department was obtained. An oral consent for sharing in the study was voluntarily obtained from each individual after explanation of the aim of the study. Strict confidentiality was carried out through all the study.

\section{Ethical approval}

The study protocol was approved by the department of Occupational and Environmental Medicine, Faculty of Medicine, Cairo University.

\section{Materials and Methods}

\section{The study design:}

This study is cross sectional prospective study.

\section{Place and duration of the study:}

This study was conducted in Rehabilitation Department at National Research Center, Cairo, Egypt from July 2013 to April 2014.

\section{The study sample}

Our studied population consisted of 68 patients who were randomly selected (simple random sample). They all underwent modified radical mastectomy and developed BCRL.

The inclusion criteria were a diagnosis of unilateral breast cancer, history of surgery, radiotherapy, diagnosis of BCRL and on conservative measures e.g., elevation of the limb, compression garments and manual massage. 
Following baseline assessment, 21 participants withdrew after 1-2 sessions and a further 25 participants withdrew before the 3-months assessment, leaving 22 participants (approximately one third of our studied population) who completed the final assessment.

\section{The Study Methods}

\section{A) Data collection Tools:}

A standardized questionnaire was administered to all subjects including personal history (age, special habit, and residence), full occupational history including the duration of work, medical history regarding the onset of BCRL after the surgical interventions and the presence of hypertension ,diabetes mellitus or any past illnesses and complaints. A full clinical examination was applied with emphasis on the upper limb with lymphydema.

We categorized the patients according to the Standard Occupation Classification system (United States Department of Labor, 2000) which is used by Federal statistic agencies to classify workers into occupational categories for the purpose of collecting, calculating, or disseminating data (United States Department of Labor).
In our classification, occupation group 1 included working continuously less than $30 \mathrm{~min}$ at a time and equal to or less than $8 \mathrm{~h}$ per day. Occupation group 2 included working continuously between 30 and $60 \mathrm{~min}$ at a time, and equal to or less than $8 \mathrm{~h}$ per day. Occupation group 3 included working continuously for more than $1 \mathrm{~h}$ and at least $8 \mathrm{~h}$ per day. 10 participants from the total 22 were categorized as occupational group II and the other 12 were classified as occupational group III. While no participant classified as group I completed the final assessment.

Age and body mass index (BMI in $\mathrm{kg} / \mathrm{m} 2$ ) of the patients were compared as continuous risk factors. Also history of breast and upper extremity infection, radiotherapy status and the side of the operation (either on the side of the dominant hand or not) were evaluated as a vital risk factors. Lymphedema grade and stage, volume of lymphedema, grip strength, restriction of shoulder movements on the operation side and arm pain were also assessed. Then all patients underwent Pneumatic compression pumping. 
Table (A) Lymphedema grades and criteria (Schrenk et al, 2000).

\begin{tabular}{|l|l|l|}
\hline Grade & Description & Characteristics \\
\hline I & Asymptomatic & No arm swelling, tightness, or heaviness \\
\hline II & Mild & $\begin{array}{l}\text { Periods of arm swelling but no constant increase } \\
\text { in greatest diameter and clothes fit the same }\end{array}$ \\
\hline III & Moderate & $\begin{array}{l}\text { Constant arm swelling and heaviness, clothes do } \\
\text { not fit the same, physical discomfort but no de- } \\
\text { crease in functional activity }\end{array}$ \\
\hline IV & Severe & $\begin{array}{l}\text { Constant arm heaviness, disability, decreased } \\
\text { functional activity, huge arm swelling }\end{array}$ \\
\hline
\end{tabular}

Table (B) Staging of breast cancer related lymphedema (Zawieja, 2005).

\begin{tabular}{|l|l|l|}
\hline Stage & Description & Characteristics \\
\hline 0 & Latent & $\begin{array}{l}\text { The lymphatic vessels have sustained some dam- } \\
\text { age which is not yet apparent. Transport capacity } \\
\text { is still sufficient for the amount of lymph being } \\
\text { removed. Lymphedema is not present }\end{array}$ \\
\hline 2 & $\begin{array}{l}\text { Spontaneously } \\
\text { reversible, } \\
\text { acute phase }\end{array}$ & $\begin{array}{l}\text { "Pitting edema" and is reversible with elevation } \\
\text { of the arm. Usually, upon waking in the morning, } \\
\text { the limb(s) or affected area is normal or almost } \\
\text { normal size }\end{array}$ \\
\hline $\begin{array}{l}\text { Spontaneously } \\
\text { irreversible, } \\
\text { chronic phase }\end{array}$ & $\begin{array}{l}\text { The tissue now has a spongy consistency and } \\
\text { is "non-pitting," meaning that when pressed by } \\
\text { fingertips, the tissue bounces back without any } \\
\text { indentation forming. Fibrosis found in stage 2 } \\
\text { lymphedema marks the beginning of the harden- } \\
\text { ing of the limbs and increasing size }\end{array}$ \\
\hline 3 & $\begin{array}{l}\text { Lymphostatic } \\
\text { elephantiasis }\end{array}$ & $\begin{array}{l}\text { At this stage the swelling is irreversible and usu- } \\
\text { ally the limb(s) is/are very large. The tissue is } \\
\text { hard (fibrotic) and unresponsive; some patients } \\
\text { consider undergoing reconstructive surgery called } \\
\text { "debulking" at this stage }\end{array}$ \\
\hline
\end{tabular}




\section{Sequential circumferential arm Procedure:}

\section{measurements}

Measuring limb size or girth or limb volume has been the most widely used diagnostic method in research. A flexible non-stretch tape measure for circumferences is usually used to assure consistent tension over soft tissue, muscle, and bony prominences (Armer and Stewart, 2005). Measurements were done on both affected and nonaffected limbs at Metacarpopharengeal joint (MPJ), wrist, $10 \mathrm{~cm}, 20,30$ and 40 above the wrist. The circumference difference between the lymphedematus limb and non affected one is calculated

\section{Visual Analog Scale (VAS)}

VAS is used to quantify pain intensity/discomfort. It's a scores range from 0 to 10 with a higher score indicating more severe pain $(0=$ "no pain" to $10=$ "severe pain") (Warden et al, 2013).

\section{Handgrip Strength Test}

The purpose of this test is to measure the maximum isometric strength of the hand and forearm muscles.
The subject holds the dynamometer in the hand to be tested, with the arm at right angles and the elbow by the side of the body. The handle of the dynamometer is adjusted if required the base should rest on first metacarpal (heel of palm), while the handle should rest on middle of four fingers. When ready the subject squeezes the dynamometer with maximum isometric effort, which is maintained for about 5 seconds. No other body movement is allowed. The subject should be strongly encouraged to give a maximum effort. The best result from several trials for each hand is recorded, with at least 15 seconds recovery between each effort (Helen et al, 2011).

\section{B) Therapeutic Tools:}

\section{Traditional Physical Therapy Program for lymphedema}

All the participants were asked to do active exercises that increase the range of motion especially while the edematous limb is bandaged. Participants were instructed for skin care to protect against infections. It consists of maintaining the affected area 
clean and dry to decrease the risk of infection. All women were instructed to do manual massage and wear pressure garment that provides pressure of (40 to $60 \mathrm{mmHg}$ ), and for $20 \mathrm{~h}$ daily during the period of the study (El-sabagh et al, 2004).

\section{Pneumatic compression device for lymphedema}

Pneumatic compression pumps are described as a treatment option for patients with lymphedema who have failed conservative measures e.g., elevation of the limb, compression garments and manual massage.

Single - chamber nonprogrammable lymphedema pump was applied on regular bases (twice per week for 12 weeks) to the limb with BCRL. The device consists of pneumatic cuffs that are connected to a pump. They use compressed air to apply pressure to the affected limb. The intention is to force excess lymph fluid out of the limb and into central body compartments in which lymphatic drainage should be preserved (BCBSA , 2003). The garment is intermittently inflated and deflated with cycle times and pressures that vary between devices, with general guidelines of $30-60 \mathrm{mmHg}$ pressure. This helps squeeze the lymph fluid through any lymph channels that are present (Hammond and Mayrovitz, 2010).

\section{Follow up interventions:}

Once the baseline assessment was done, all subjects were asked to modify their daily use of their upper extremities to the first level according to the standard occupation classification system( upper extremities are used less than $30 \mathrm{~min}$ at a time and equal to or less than $8 \mathrm{~h}$ per day) to prevent increased severity of BRCL.

Pneumatic compression pumping was done to reduce the upper limb volume. Each patient received 2 sessions weekly during the 12 weeks and each session lasted $30 \mathrm{~min}$. In each session, the affected upper limb was placed in the compression pump for $15 \mathrm{~min}$. Then the affected limb was bandaged with multilayer compression bandages to increase the lymph circulation.

During these sessions, written and verbal information were provided regarding decreasing the duration of continuous work to be less than half 
an hour at a time and health education and empowering patients with the best way to cope their occupational needs, performing physical exercise according to the general exercise guidelines (Kwan et al, 2011): including whole body exercises (walking, running), the importance of continuing their conservative measures, the value of adherence to risk reduction behaviors, optimal weight management, skin and nail care to prevent infections and how to bandage the upper limb.

At the end of 12 weeks follow up, limb volume evaluated via limb circumference, and symptom control and upper extremity function evaluated via visual analogue scales, hand grip and shoulder restriction were assessed again in only 22 patients(10 patients group II and 12 group III, without group I) and compared to baseline.

\section{Statistical analysis}

Data obtained from the study was coded and entered using the statistical package SPSS version 16. The mean values, standard deviation (SD) and ranges were then estimated for quantitative variables. For the qualitative variables, the frequency distribution was calculated.
Comparisons among the occupational groups were done using Chi square $(\chi 2)$ test for qualitative variables and using the independent simple t-test as well as the analysis of variance (ANOVA test) for normally distributed quantitative variables. $\mathrm{P}$-values less than 0.05 were considered statistically significant.

\section{Results}

The study population consisted of 68 female patients with BCRL. The mean age and BMI of the studied group were $(48.80 \pm 7.21,33.41 \pm 5.08$ consequently) $23.5 \%$ were hypertensive and $20.6 \%$ were diabetics. $50 \%$ of them did the operation on the dominant hand and $58.8 \%$ had history of infection in the affected limb.The Mean Muscle Strength of left (Lt) and right (Rt) hand were $18.13 \pm 5.72,19.23 \pm 7.49$ consequently while regarding VAS, it was $4.85 \pm 1.87$.

The selected studied group was divided into three occupational groups according to the Standard Occupation Classification system 2000. 1st group $(n=12), 2^{\text {nd }}$ group $(n=29) \quad 3^{\text {rd }}$ group 
$(n=27)$. The difference of sequential

Among the $100 \%$ adherent $(n=22)$ circumferential measurements between two occupational groups (group II the affected and non affected limb at $n=10$ and group III $n=12$ ) pre and MPJ ,wrist, $10 \mathrm{~cm}, 20 \mathrm{~cm}, 30 \mathrm{~cm}$ and post interventions, there were no $40 \mathrm{~cm}$ among the three group before changes in the clinical grade and intervention revealed significant stage of lymphedema. Also there was difference $(\mathrm{P}<0.05)$ at all levels except improvement in shoulder restriction but MPJ ( $F=2.6,9.7,19.1,26.2,26.2,16.4$ not to the significant level $\left(\mathrm{X}^{2}=1.18\right.$, respectively). 0.73 respectively). 
Table (1): Frequency distribution of diabetes mellitus (DM), hypertension (HTN), Operation on dominant hand, history of infection and shoulder restriction among the three occupational groups.

\begin{tabular}{|c|c|c|c|c|c|}
\hline & $\begin{array}{c}\text { Occupational } \\
\text { group I } \\
\text { No:12 }\end{array}$ & $\begin{array}{c}\text { Occupational } \\
\text { group II } \\
\text { No:29 }\end{array}$ & $\begin{array}{c}\text { Occupational } \\
\text { group III } \\
\text { No:27 }\end{array}$ & X2 & P Value \\
\hline DM & 2 & 6 & 6 & 0.15 & $>0.05$ \\
\hline Hypertension & 4 & 8 & 4 & 2.04 & $>0.05$ \\
\hline $\begin{array}{c}\text { Operation on } \\
\text { dominant hand }\end{array}$ & 8 & 10 & 16 & 5.05 & $>0.05$ \\
\hline Infection & 10 & 13 & 17 & 5.51 & $>0.05$ \\
\hline $\begin{array}{c}\text { Shoulder } \\
\text { restriction }\end{array}$ & 8 & 22 & 16 & 1.76 & $>0.05$ \\
\hline
\end{tabular}

DM: diabetes Mellitus

Table (1) shows that there is no statistical significant differences were detected among the all variables $(\mathrm{P}$ value $>0.05)$.

Table (2): Frequency distribution of different grades and stages of lymphedema among the three occupational groups.

\begin{tabular}{|c|c|c|c|c|c|}
\hline lymphedema & $\begin{array}{c}\text { Occupational } \\
\text { group I } \\
\text { No:12 }\end{array}$ & $\begin{array}{c}\text { Occupational } \\
\text { group II } \\
\text { No:29 }\end{array}$ & $\begin{array}{l}\text { Occupational } \\
\text { group III } \\
\text { No: } 27\end{array}$ & $\mathrm{X} 2$ & P Value \\
\hline \multirow{3}{*}{$\begin{array}{c}\text { Grade II } \\
\text { III } \\
\text { IV }\end{array}$} & 12 & 4 & 0 & \multirow[t]{3}{*}{74.81} & \multirow[t]{3}{*}{$<0.05^{*}$} \\
\hline & - & 25 & 11 & & \\
\hline & - & - & 16 & & \\
\hline \multirow{3}{*}{$\begin{array}{c}\text { Clinical Stage II } \\
\text { III } \\
\text { IV }\end{array}$} & 12 & 15 & 1 & \multirow[t]{3}{*}{44.34} & \multirow[t]{3}{*}{$<0.05^{*}$} \\
\hline & - & 14 & 14 & & \\
\hline & - & - & 12 & & \\
\hline
\end{tabular}

*significant difference 
Table (2) shows the different grades and stages of lymphedema, 16 patients of occupational group III had grade IV lymphydema and 12 patients of the same group had stage IV lymphydema with statistically significant differences among the three occupational groups.

Table (3): Mean and SD of age, BMI, Onset of edema, radiotherapy sessions, right and left hand grip and VAS among the three occupational groups.

\begin{tabular}{|c|c|c|c|c|c|}
\hline & $\begin{array}{c}\text { Occupational } \\
\text { group I } \\
\text { No:12 } \\
\text { Mean } \pm \text { SD }\end{array}$ & $\begin{array}{c}\text { Occupational } \\
\text { group II } \\
\text { No:29 } \\
\text { Mean } \pm \text { SD }\end{array}$ & $\begin{array}{c}\text { Occupational } \\
\text { group III } \\
\text { No:27 } \\
\text { Mean } \pm \text { SD }\end{array}$ & F & P Value \\
\hline Age(years) & $49.58 \pm 6.00$ & $50.27 \pm 6.99$ & $46.88 \pm 7.73$ & 1.65 & $>0.05$ \\
\hline BMI (kg/m2) & $33.52 \pm 2.43$ & $32.89 \pm 5.37$ & $33.91 \pm 5.70$ & 0.28 & $>0.05$ \\
\hline $\begin{array}{c}\text { Onset of oedema } \\
\text { (months) }\end{array}$ & $17.00 \pm 6.98$ & $15.51 \pm 13.48$ & $10.44 \pm 7.38$ & 2.36 & $>0.05$ \\
\hline $\begin{array}{c}\text { Radiotherapy(no. } \\
\text { of session) }\end{array}$ & $15.41 \pm 7.82$ & $13.27 \pm 7.7$ & $17.03 \pm 8.57$ & 1.52 & $>0.05$ \\
\hline $\begin{array}{c}\text { Rt Hand grip } \\
\text { (Newton) }\end{array}$ & $16.66 \pm 4.92$ & $19.10 \pm 7.80$ & $20.51 \pm 8.01$ & 1.10 & $>0.05$ \\
\hline Lt Hand grip & $18.33 \pm 6.51$ & $16.72 \pm 5.12$ & $19.55 \pm 5.81$ & 1.75 & $>0.05$ \\
\hline VAS & $4.33 \pm 0.98$ & $5.00 \pm 1.94$ & $4.92 \pm 2.11$ & 0.56 & $>0.05$ \\
\hline
\end{tabular}

VAS: Visual Analogue Scale

Table (3) shows that there is no statistical significant differences were detected among the all variables ( $\mathrm{P}$ value $>0.05)$. 
Table (4): Mean and SD of VAS, right and left hand grip and the difference of sequential circumferential measurements between the affected and non affected limb among the adherent two occupational groups pre and post interventions

\begin{tabular}{|c|c|c|c|c|c|}
\hline & & $\begin{array}{c}\text { Pre } \\
\text { interventions }\end{array}$ & $\begin{array}{c}\text { Post } \\
\text { interventions }\end{array}$ & $\mathrm{T}$ & $\mathrm{P}$ value \\
\hline \multirow{2}{*}{ VAS } & $\begin{array}{c}\text { Group II } \\
\text { Mean } \pm \text { SD } \\
(\mathrm{n}=10)\end{array}$ & $4.40 \pm 1.07$ & $4.20 \pm 0.91$ & 0.44 & $>0.05$ \\
\hline & $\begin{array}{c}\text { Group III } \\
\text { Mean } \pm \text { SD } \\
(\mathrm{n}=12)\end{array}$ & $5.41 \pm 1.83$ & $3.91 \pm 0.79$ & 2.60 & $<0.05^{*}$ \\
\hline \multirow{2}{*}{$\begin{array}{l}\text { Rt hand } \\
\text { grip }\end{array}$} & Group II & $16.80 \pm 7.84$ & $19.60 \pm 5.91$ & 0.90 & $>0.05$ \\
\hline & Group III & $16.16 \pm 3.04$ & $18.58 \pm 2.57$ & 2.10 & $<0.05^{*}$ \\
\hline \multirow{2}{*}{$\begin{array}{l}\text { Lt hand } \\
\text { grip }\end{array}$} & Group II & $13.70 \pm 4.83$ & $13.30 \pm 3.30$ & 0.21 & $>0.05$ \\
\hline & Group III & $17.66 \pm 3.55$ & $16.83 \pm 3.48$ & 0.58 & $>0.05$ \\
\hline \multirow{2}{*}{ MPJ } & Group II & $2.00 \pm 1.76$ & $1.90 \pm 1.66$ & 0.13 & $>0.05$ \\
\hline & Group III & $0.83 \pm 0.71$ & $0.66 \pm 0.65$ & 0.59 & $>0.05$ \\
\hline \multirow{2}{*}{ Wrist } & Group II & $0.6 \pm 0.51$ & $0.50 \pm 0.52$ & 0.42 & $>0.05$ \\
\hline & Group III & $1.50 \pm 1.31$ & $1.25 \pm 0.96$ & 0.53 & $>0.05$ \\
\hline \multirow{2}{*}{$10 \mathrm{~cm}$} & Group II & $4.00 \pm 1.33$ & $3.90 \pm 1.28$ & 0.17 & $>0.05$ \\
\hline & Group III & $6.08 \pm 2.60$ & $5.66 \pm 2.53$ & 0.39 & $>0.05$ \\
\hline \multirow{2}{*}{$20 \mathrm{~cm}$} & Group II & $2.00 \pm 0.66$ & $1.90 \pm 0.73$ & 0.31 & $>0.05$ \\
\hline & Group III & $5.83 \pm 2.36$ & $5.50 \pm 2.06$ & 0.36 & $>0.05$ \\
\hline
\end{tabular}




\begin{tabular}{|c|c|c|c|c|c|}
\hline \multirow{2}{*}{$30 \mathrm{~cm}$} & Group II & $3.80 \pm 1.39$ & $3.70 \pm 1.41$ & 0.15 & $>0.05$ \\
\cline { 2 - 6 } & Group III & $5.50 \pm 1.88$ & $6.16 \pm 1.99$ & 0.42 & $>0.05$ \\
\hline \multirow{2}{*}{$40 \mathrm{~cm}$} & Group II & $3.20 \pm 2.52$ & $3.10 \pm 2.46$ & 0.08 & $>0.05$ \\
\cline { 2 - 6 } & Group III & $6.25 \pm 2.49$ & $6.08 \pm 2.71$ & 0.15 & $>0.05$ \\
\hline
\end{tabular}

VAS: Visual Analogue Scale

MPJ: Metacarpopharengeal Joint

Table (4) shows mean and SD of VAS, right and left hand grip and the difference of sequential circumferential measurements between the affected and non affected limb at MPJ, wrist, $10 \mathrm{~cm}, 20,30$ and 40 above the wrist among the $100 \%$ adherent $(n=22)$ two occupational groups (group II $n=10$ and group III $n=12$ ) pre and post interventions. Statistical significant decrease was detected regarding The VAS and significant increase in Rt hand grip was observed among group III. While the difference of sequential circumferential measurements showed decrease in their values but not to the significant level. 


\section{Discussion}

Lymphedema of the arm following breast cancer treatment continues to be a distressing and frequent problem. The development of lymphedema after breast cancer treatment is most likely multifactorial. Risk factors that are directly related to breast cancer treatment may be mostly inescapable for patients treated for breast cancer, including breast surgery (lumpectomy and mastectomy), removal of lymph nodes (sentinel lymph node biopsy and axillary lymph node dissection), radiotherapy, or chemotherapy. There are also known risk factors that are not directly related to breast cancer treatment. These risk factors may actually be modified, such as obesity, weight gain after diagnosis, minor upper extremity infections, injury or trauma to the affected limb, or overuse of the limb (Lawenda et al, 2009 and McLaughlin et al,2013).

Commonly reported risk factors for breast cancer related lymphedema include infection of the arm, elevated body mass index (BMI), and level of hand use. Inflammation-infection and higher body mass index (BMI) are from the main predictors of limb volume change (Lawenda et al, 2009). Women who had previous inflammationinfection in the breast, chest, or arm were 3.8 times more likely to develop lymphedema (Mak et al, 2008). This possibly because infection will further damage lymphatic and delay the lymphatic reconstruction and establishment of collateral circulation (Zhu et al,2014).

Also weight gain and obesity (BMI $>30 \mathrm{~kg} / \mathrm{m} 2$ ) increases lymphedema risk (National Cancer Institute, 2008). Survivors with each increase of $1 \mathrm{~kg} / \mathrm{m} 2$ in their BMI were 1.11 times more at risk for developing lymphedema (Mak et al, 2008). In the current study, we found increased BMI $(33.41 \pm 5.08)$ in our studied group. Actually obesity may alter risk of lymphedema via increased stress to the lymphatics, enhanced inflammation, increased trauma, or prolonged healing from surgery.

Diabetes mellitus and hypertension as co morbid conditions were also evaluated. We found that 14 subjects were diabetic and 16 were hypertensive it's well-known that uncontrolled DM increase the risk of infections. Deo et al 
in 2004 mentioned that there is a positive association between comorbidity (diabetes mellitus, hypertension, chronic renal failure, congestive heart failure, myxedema) and lymphedema. However, other study had not observed associations between lymphedema and hypertension or diabetes mellitus (Soran et al, 2006).Regarding the age as a risk factor, the mean value was $48.80 \pm 7.21$. Clough et al., in 2010 mentioned that lymphatic venous anastomosis will decrease with increasing of age and the lymphatic drainage compensatory capacity also decreases.

Internationally accepted guidelines (e.g., American Cancer Society; ACS) recommend that women adopt selfmanagement strategies to minimize strain on the lymphatic system through avoidance of infection, , lifting children or heavy objects with the affected arm, trauma to the arm, excessive muscle strain, and weight gain (Vignes et al,2007). Some studies do not support the hypothesis that exercise training results in increased lymph clearance as measured by lymphoscintigraphy (Lane et al, 2007 and Zawieja, 2005). However Schmitz et al. in 2009 mentioned that in clinical practice, these guidelines often translates into avoiding usage the arm. This could lead to a disuse pattern that may increase the likelihood of injury from common activities of daily living. Further, such guidance poses an additional barrier to staying physically active, potentially translating to weight gain, which has been shown to be associated with worse clinical course for women with lymphedema. They recommended slowly progressive weight lifting training to increase the physiologic capacity of the arm. Actually an optimal use of weightlifting by breast-cancer survivors with lymphedema is still a question. Kwan et al in 2011 reported that performing physical exercise according to the general exercise guidelines including whole body exercises (walking, running) will be of great benefit as it supports weight control, physical fitness, positive emotion, and quality of life.

It was reported that the occupation of patients which determine the level of hand use is one of the important risk factor for BCRL (Gur et al, 2009).In the current work; we applied the standard 
occupation classification system 2000 depending on the time of continuous hand usage and the daily total work period. In our three occupation groups, all risk factors( age, BMI, DM, HTN, history of infections, number of radiotherapy sessions and operation on dominant hand) were distributed among them without statistically significant difference( $\mathrm{P}>0.05)$ while the grade and stage of lymphedema were more severe in the heavy work group( group III). Accordingly, we can propose that occupation is a vital risk factor for increased severity of BRCL and occupations require more upper extremity activity with long period of work had an autonomous risk for more severe disease outcome. This goes in accordance to the finding of Tahan et al, 2010 who studied The role of occupational upper extremity use among fifty-five women with BCR .They also used the standard occupation classification system 2000. They found that occupations that require greater use of the upper extremities are associated with advanced clinical stage and grade of lymphedema. Further, Soran et al, 2006 studied the significant predictors of BRCL on 52 women and how they affect its severity. They categorized the level of hand use into low, medium, and high. They found that the corresponding frequencies were $33 \%, 14 \%$ and 53\% for patients with mild lymphedema and $33 \%, 11 \%, 56 \%$ for patients with moderate/severe lymphedema ( $\mathrm{p}<$ $0.05)$.They concluded that the risk and severity of lymphedema was statistically related to level of hand use. However, Johansson et al, 2002 found that no statically significant difference in occupational workload among breast cancer patients with or without lymphedema, .They concluded that women treated for breast cancer could maintain their level of occupational workload without an added risk of developing arm lymphedema.

In deed all risk factors affect the onset of lymphedema. In our work we detected that the earlier onset was in group III followed by group II then group I (the mean value in months = $10.44,15.51,17.00$ respectively) but the difference wasn't to the significant level. This goes in accordance to the findings of Zue et al ,2014 who showed that the axillary lymph node dissection, postoperative complications, 
hypertension, body mass index, post operative treatments, employment status, age, treatment on dominant side are risk factors for lymphedema and affect its onset.

In this study, the arm pain detected by VAS and shoulder restriction of our participants didn't show significant difference between the three occupational groups before intervention (Table 1\&3). However Tahan et al, 2010 found that the patient's occupation is not only an autonomous risk factor for BRCL but also a valuable indicator for further BCRL related symptoms (shoulder restriction and arm pain) and therapy needs (physiotherapy and pain medicine needs).Regarding our results, this could be explained by the variable pain threshold among our studied group although the pain intensity was not high enough in group III.

Once BCRL is established, there is no cure. Management of lymphedema focuses on swelling reduction and symptom improvement (Mei, 2014). There is no ideal treatment available for established lymphedema and future efforts focus on optimizing treatment combinations. In the current work we measured the volume of lymphydema using the sequential circumferential arm measurements which revealed significant increase in patients classified as occupational group III compared to the other two group at almost all levels. Once applying our interventional work, reassessment of lymphedema among the $100 \%$ adherent group $(n=22)$ showed a decrease in the limb volume but this reduction didn't reach the significant level. It's worth to mention that there wasn't any progression in the lymphedema volume in any participant. However, this could be explained by the multfactorial risk aspect of lymphedema which could contribute to its volume. This goes in accordance to the results of Shao et al, 2014 who showed that the use of the pneumatic (compressive) pumps could alleviate lymphedema, but not to the significant level. However, Szuba et al. in 2002 concluded that, combined decongestive therapy (CDT) along with compression pumping reduced the limb volume more effectively than CDT alone. Also Feldman et al, 2012 mentioned that pneumatic pumps can reduce swelling. They added that it decreases tissue capillary filtration rate and lymph 
formation (but lymph transport is not improved) and, consequently, causes reduction in the limb volume. Further Muluk et al., 2013 demonstrated that Pneumatic Compression Device treatment can reduce Limb Volume and improve pain. Thus, patients with lymphedema enjoyed an improved quality of life .They reported that Pneumatic Compression Device used for the treatment of acute and chronic peripheral lymphedema to facilitate the mobilization of fluid from the limbs.

In the current work improvement of symptoms was detected after applying the interventional work. Shoulder restriction was improved but not to the significant level. Significant reduction of VAS was noticed. This could be explained by the mild improvement in lymphedama. Not only there was improvement in arm pain but also there was significant increase in the Rt handgrip. This could be clarified by the findings of Lee et al, 2015 who studied factors related to arm weakness in 80 patients with BRCL. They found that weakness of the arm with lymphedema was not related to lymphedema itself, but was related to the fear of using the affected limb. They concluded that appropriate physical and psychological interventions, including providing accurate information and reassurance of physical activity safety, are necessary to prevent arm weakness and physical dysfunction in patients with BRCL.

\section{Conclusion and Recommendations}

In conclusion, occupations requiring more upper extremity activity had the worst lymphedema clinical grade and stage status. Hence occupation related classification could be helpful in risk predict and prognosis of BCRL. Patient's occupation could be considered as a reliable marker to predict higherrisk conditions in follow-up and these patients should be informed to adjust their daily use of their upper extremities to prevent increased severity of BRCL. Besides the combined effect of decreased occupational work load of the upper extremities and the use of pneumatic compression pumps needs to be more investigated

Although our study shows excessive use of the upper extremities at work is associated with more severe stage and grade in BCRL. Some limitations were faced that make our results uncertain 
until further research is conducted. First, we conducted analysis of the patients who were already diagnosed with lymphedema, second, we did not have all variables might affect the severity of lymphedema, and third, the limited number of the adherent subjects to our interventional work. Therefore, large scale prospective study is recommended.

\section{Conflict of interest:}

Authors have declared that no conflict of interests exists.

\section{References}

1. Armer JM, Hulett JM, Bernas M, Ostby P, Stewart BR, Cormier JN (2013): Best-Practice guidelines in assessment, risk reduction, management, and surveillance for post-breast cancer lymphedema. Curr Breast Cancer Rep; 5:134-144.

2. Armer JM and Stewart BR (2005): A comparison of four diagnostic criteria for lymphedema in a post-breast cancer population. Lymphatic Res Bio; 3:208-217.

3. BCBSA (2003): Medical Policy Reference Manual [Electronic Version]. 1.01.18,

4. Clough-Gorr KM, Ganz PA, Silliman RA (2010): Older breast cancer survivors: factors associated with self-reported symptoms of persistent lymphedema over 7 years of followup. Breast J; 16: 147-55.

5. Deo SV1, Ray S, Rath GK, Shukla NK, Kar M, Asthana S and Raina V (2004 ): Prevalence and risk factors for development of lymphedema following breast cancer treatment. Indian $\mathrm{J}$ Cancer.; 41(1):8-12.
6. El-sabagh RM, Mersal AE and Taher MO (2004): Treatment of post mastectomy lymphedema with exercises and compression garment versus compression garment. Proceedings from the 7th International Scientific Conference of Faculty of Physical Therapy, Cairo, Egypt, March 4-5.

7. Feldman JL, Stout NL, Wanchai A, Stewart BR, Cormier JN and Armer JM. (2012): Intermittent pneumatic compression therapy: a systematic review. Lymphology; 45: 13-25

8. Gur SA, Unal B, Ahrendt G, Gimbel ML, Kayiran O, Johnson R, et al. (2009): Risk factor for breast cancer-related upper extremity: is immediate autologous breast reconstruction one of them? Cent Eur J Med; 4:65-70.

9. Hammond TM and Mayrovitz HN (2010): Programmable intermittent pneumatic compression as a component of therapy for breast cancer treatment-related truncal and arm lymphedema. Home Health Care Management Practice; 22(6):397-402

10. Helen CR, Hayley JD, Helen JM, Harnish PP, Holly S, Cyrus C and Avan AS (2011): A review of the measurement of grip strength in clinical and epidemiological studies: towards a standardized approach. Age Ageing; 40 (4): 423-429.

11. Johansson K, Ohlsson K, Ingvar C, Albertsson $\mathrm{M}$ and Ekdahl C (2002): Factors associated with the development of arm lymphedema following breast cancer treatment: a match pair casecontrol study. Lymphology; 35(2):59-71.

12. Kaviani A and Lotfi M. (2006): Control of lymphedema after breast cancer treatment. 1st ed. Tehran: Tehran University of Medical Sciences; Pp.13-74.

13. Kwan ML, Cohn JC, Armer JM, Stewart BR and Cormier JN (2011): Exercise in patients with lymphedema: A systematic review of the contemporary literature. J Cancer Surv; 5:320336 . 
14. Lane KN, Dolan LB, Worsley D and McKenzie DC (2007): Upper extremity lymphatic function at rest and during exercise in breast cancer survivors with and without lymphedema compared with healthy controls. J Appl Physiol; 103:917-925.

15. Lawenda BD, Mondry TE and Johnstone PA (2009): Lymphedema: a primer on the identification and management of a chronic condition in oncologic treatment. CA Cancer J Clin; 59:8-24.

16. Lee DL, Hwang JH, Chu I, Chang HJ, Shim YH and Kim JH. (2015): Analysis of factors related to arm weakness in patients with breast cancerrelated lymphedema. Support Care Cancer. 23(8): 2297-2304.

17. Mak SS, Yeo W, Lee YM, Mo KF, Tse KY, Tse SM, Ho FP and Kwan WH (2008): Predictors of lymphedema in patients with breast cancer undergoing axillary lymph node dissection in Hong Kong. Nurs Res; 57:416-425.

18. McLaughlin SA, Bagaria S, Gibson T, Arnold M, Diehl N, Crook J, Parker A and Nguyen J (2013): Trends in risk reduction practices for the prevention of lymphedema in the first 12 months after breast cancer surgery. J Am Coll Surg; 216:380-389.

19. Mei R F (2014): Breast cancer-related lymphedema: Symptoms, diagnosis, risk reduction, and management World $\mathrm{J}$ Clin Oncol; 5(3): 241-247.

20. Mortimer PS (1998): The pathophysiology of lymphedema. Cancer; 83(12 Suppl American):2798-802 .

21. Muluk SC, Hirsch AT and Taffe EC (2013): Pneumatic compression device treatment of lower extremity lymphedema elicits improved limb volume and patient-reported outcomes. Eur J Vasc Endovasc Surg; 46(4):480-7

22. National Cancer Institute (2008): Lymphedema (PDQR). http://www.cancer.gov/cancertopics/ $\mathrm{pdq} / \mathrm{su}$ p portivecare/1 y m phedema/ HealthProfessional/page2.
23. National Cancer Institute (2014): Lymphedema (PDQ). Available online:www.cancer.gov/ cancertopics/pdq/supportivecare/lymphedema/ healthprofessional

24. National Lymphedema Network (2008): Medical Advisory Committee Topic, Lymphedema Risk Reduction Practices. Journal. [Accessed on: March 2008]; Internet. cited 2008 ( Sept 17). Available http://www. lymphnet.org/pdfDocs/nlnriskreduction.pdf.

25. Rezaianzadeh A, Peacock J, Reidpath D, Talei A, Hosseini SV and Mehrabani D (2009): Survival analysis of 1148 women diagnosed with breast cancer in Southern Iran. BMC J Can; 9:168.

26. Schmitz KH, Troxe AB, Cheville A, Grant LL, Bryan CJ, Gross C, Lytle LA and Ahmed RL (2009): Physical Activity and Lymphedema (The PAL Trial): Assessing the safety of progressive strength training in breast cancer survivors. Contemp Clin Trials; 30(3): 233-245.

27. Schrenk P, Rieger R, Shamiyeh A and Wayand W (2000): Morbidity following sentinel lymph node biopsy versus axillary lymph node dissection for patients with breast carcinoma. Cancer; 88:608-14.

28. Shah C and Vicini FA (2011): Breast cancerrelated arm lymphedema: incidence rates, diagnostic techniques, optimal management and risk reduction strategies. Int J Radiat Oncol Biol Phys; 81:907-14.

29. Shao Y, Qi K, Zhou QH and Zhong DS (2014): Intermittent pneumatic compression pump for breast cancer-related lymphedema: a systematic review and meta-analysis of randomized controlled trials. Oncol Res Treat.; 37(4):170-4.

30. Soran a, D'Angelo G, Begovic M, Ardic F, Harlak a, Samuel Wieand H, et al. (2006): Breast cancer-related lymphedema-what are the significant predictors and how do they affect the severity of lymphedema? Breast J; 12:536-43. 
31. Szuba A, Achalu R and Rockson SG (2002): Decongestive Lymphatic Therapy for Patients with Breast Carcinoma-Associated Lymphedema. Cancer; 95:2260-70.

32. Tahan G, Johnson R, Mager L and Soran A (2010): The role of occupational upper extremity use in breast cancer related upper extremity lymphedema. J Cancer Surviv; 4(1):15-9.

33. United States Department of Labor (2000): Bureau of Labor Statistics Standard Occupation Classification. http://www.bls.gov/SOC

34. Vignes S, Arrault M and Dupuy A (2007): Factors associated with increased breast cancer- related lymphedema volume. Acta Oncol; 46(8):1138-42.

35. Warden V, Hurley AC and Volicer L (2003): Development and psychometric evaluation of the pain assessment in advanced dementia (PAINAD) scale. Journal of the American Medical Directors Association; 4:9-15

36. Zawieja D (2005): Lymphatic biology and the microcirculation: past, present and future. Microcirculation; 12:141-150

37. Zhu YQ1, Xie YH, Liu FH, Guo Q, Shen PP and Tian Y (2014): Systemic analysis on risk factors for breast cancer related lymphedema. Asian Pac J Cancer Prev; 15(16):6535-41. 